\title{
Power Changeover Technologies for Networking and Telecom Power Systems
}

\author{
C. Rajabhushnam,. B Sundar Raj, Sri vidhya
}

\begin{abstract}
Innovation for control frameworks of present day PC/organizing/telecom hardware is confronting to a great degree intense difficulties because of ceaselessly expanding power-thickness and proficiency necessities. Meeting these necessities will require huge innovation headways in framework models, gadgets and materials, topology streamlining, and bundling/warm plan. In this paper, significant innovation difficulties and future patterns in every one of these key innovation territories are recognized and quickly talked about.
\end{abstract}

Keywords: ceaselessly expanding, topology streamlining, key innovation territories.

\section{INTRODUCTION}

As far back as the beginning of the scaling down time allotment influenced on by the microelectronics change in the late fifties and mid-sixties, control change gear utilized in PC and media transmission control structures has been going toward continually developing power thickness and proficiency challenges. Regardless, It was not until the introduction of high-voltage bipolar junction point control transistors in the early sixties, which rendered it conceivable to supplant direct power supplies with high-rehash switch-mode control systems, that a real open gate had been created to reduce time and weight and to expand the advantage of essential shift circuits.

Everything considered, Straight advancement of the power supply does not give a basic open door to reduce weight and size in light of the fact that the size and weight is commonly compelled by the line-rehash transformer and warmth sink. Besides, the chances to improve the proficiency are in addition unimaginably restricted in light of the manner in which that the capacity of straight power supplies is settled exclusively by the degree of the yield and information voltage. Then again, switch-mode control supply progression offers an enormous size and weight diminishing since it gets out the need for tremendous line-rehash magnetics what's more decreases the extent of warmth soaks in light of a much improved sufficiency showed up distinctively in connection

Revised Manuscript Received on October 22, 2019.

C. Rajabhushnam, Department of Computer Science and Engineering, Bharath Institute of Higher education and research, Chennai , India

B Sundar Raj, Department of Computer Science and Engineering, Bharath Institute of Higher education and research, Chennai , India

Sri vidhya, Department of Computer Science and Engineering, Bharath Institute of Higher education and research, Chennai , India to that of direct power supplies. Everything considered, the capacity and size streamlining of switch-mode control supplies depends after finding an exchanging rehash.

Though bipolar-crossing point transistor-based switch-mode control supply advancement has accomplished exciting force thickness changes appeared differently in relation to straight power supply development, furthermore control thickness augmentations were engaged by the introduction of vitality MOSFET devices in the early seventies. The MOSFET development together with movements in control magnetics made it possible to in a general sense fabricate the trading repeat and, as such, decrease the degree of appealing portions. While the recurrent degree of early switch mode control supplies executed with bipolar intersection point control gadgets was obliged to two or three kilohertz. Since the most ludicrous exchanging rehash of a power converter is identified with its yield control level, input voltage go, and galvanic partition necessities, the basic exchanging rehash the degree of dc-dc converters is greater than the degree of isolate converters as shown in Fig. 1. From Fig as can be seen. 1, the present low-control, non-pulled back voltage controllers (VRs) and explanation behind stack (POL) converters whose data voltage is in the $5-\mathrm{V}$ to $12-\mathrm{V}$ run work at exchanging frequencies more than $1 \mathrm{MHz}$, anyway cooling dc converters that require transformer separation and whose rms line voltage is from $90 \mathrm{~V}$ to $265 \mathrm{~V}$ consistently work with exchanging frequencies in the $70-200-\mathrm{kHz}$ go.

\section{CHANGE IN PERSPECTIVE}

Up to this point, proficiency increments of energy transformation circuits were principally determined by expanded power thickness prerequisites since control thickness increments are just conceivable if suitable incremental upgrades in full-stack productivity are accomplished with the goal that the warm and acoustic execution are not unfavourably influenced. Therefore, augmentation of the full-stack effectiveness has been a plan concentrate from the beginning. Be that as it may, in the mid-nineties, the hazardous development of shopper gadgets and information preparing hardware had provoked the presentation of different, generally intentional, necessities went for limiting the site without moving mode. Imperativeness Star, Japan Top Runner, and ECoC (European Code of Conduct) judgments[2], poses critical design problems for production manufacturers to regulate. Appropriately, both power supply producers and energy suppliers committed colossal to making advances to agree to these specifics. 
Today, the power supply sector is near to the start of an imperative focus step that places adequacy overhaul over the full burden on the front line of the essential execution of clients. This consideration on capability has been incited by money related reasons and typical concerns brought about by the determined, powerful advancement of the Internet system and a for the most part low essentialness viability of vitality transport structures of immense Internet-gear encouraging workplaces.

\section{INNOVATION CONSIDERATIONS}

The real exercises went for enhancing the execution of the power transformation and conveyance arrangement of information preparing and telecom hardware are constantly cantered around four key innovation regions. While in the past the licensed implementation redesigns were mainly grown by refinements in control converter topologies and types of development in semiconductors and charming products, potential sufficiency and energy density adjustments are relying mostly on the structural scheme. and power association improvement, and in like manner from developments in bundling and warm association approachs. As such, the current R\&D center has moved from converter-level topology streamlining to structure level structure improvement and execution of weight action based power association. Seeing that power association (PM) limit will be a target and essential piece of future power frameworks; the moved power association transport has as of late been managed by PMBus Implementers Forum. Eventually, different suppliers of ICs for control change applications have displayed PMBus pleasing things. Despite PMBus consistence, the bigger piece of these ICs offer propelled control as well. All around, while modernized control organization can propel execution at the structure level, Propelled control makes it feasible to streamline the profitability of the converter level throughout the full load transfer by making versatile, stacking subordinate control estimates and, in addition, adaptable switch time control. Furthermore, the control, monitoring, safety and housekeeping functions of vitality converters are shifted from hardware to programming with electronic growth which through and through truncates thing arrangement time, diminishes the expense, and besides thinks about straightforward change (tweaking) of parameters even after the thing is sent.

\section{A.Architecture}

By and large, control conveyance frameworks of information preparing and media transmission gear are worked around two particular designs - unified and appropriated control engineering (DPA). At the framework level, control conveyance frameworks utilized in server farms and telecom offices are innately dispersed as a result of the circulated idea of the heap.

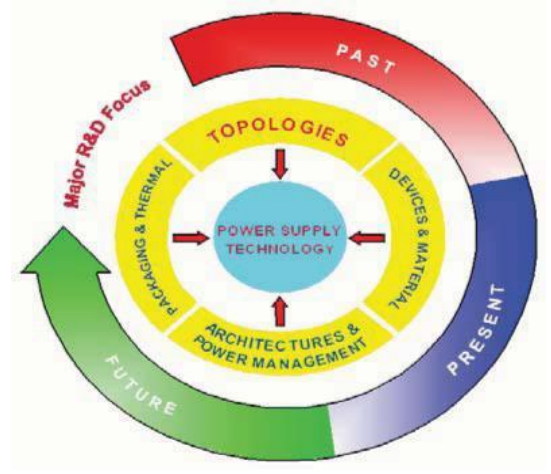

As outlined in Fig. 4(a), DPA in server farms utilizes air conditioning transport dissemination, though telecom offices utilize - 48-V DPA with dc-transport conveyance. At the hardware level, brought together power design (CPA) has been only utilized in taken a toll touchy, low-to-medium power applications, for example, PCs and workstations, though in high-control frameworks, for example, centralized server PCs and top of the line servers, and in addition in systems administration gear, dc-transport appropriated control engineering has been utilized.

\section{B. Topologies}

As far back as the presentation of switch-mode control supplies, the major R\&D exertion has been centered around discovering topologies that offer improved change efficiencies and power densities. In the late seventies and on timetable to-mid-eighties, the chance to all things considered reducing the extent of essentialness converters by broadening the exchanging rehash that was made by dependably progressing MOSFET advancement had run topology improvement and progress rehearses on the diminishment of exchanging fiascos of the semiconductor gadgets, Considered to be a notable obstacle to boosting the repetition of "tough" heartbeat (PWM) converters traded. Overall, this wide-ranging $R \& D$ project has been placed around the resonant energy shift that has led to the enhancement of fresh complete converter meetings over the long run.

\section{Segments and Materials}

By and large, headways in semiconductor innovation have dependably been the real push behind proficiency and power thickness changes in control transformation circuits. In particular, the sensational changes in air conditioning/dc control supply execution that have been proficient in the earlier decade or so have been essentially realized by unprecedented decrease of the on-protection of high-voltage MOSFETs and similarly amazing upgrades backward recuperation qualities of high-voltage silicon ( $\mathrm{Si}$ ) rectifiers. For instance, the super-intersection innovation has empowered a diminishment of the on-protection of the present $600-\mathrm{V}$ MOSFETS down to $45 \mathrm{~m}$, which is around ten times bring down contrasted with the on-protection of best in class $600-\mathrm{V}$ gadgets accessible in the nineties [56]. So also, the present high-voltage $\mathrm{Si}$ rectifiers show an altogether 
bring down invert recuperation charge, which has enhanced productivity and improved the plan of the lift PFC front end in air conditioning/dc control supplies. In high output voltage apps, efficacy modifications have been created conceivable by consistently decreasing the on-protection of low voltage MOSFETs used as synchronous rectifiers.

\section{Bundling}

Headways in bundling innovation and warm administration will be of principal significance for future power-thickness changes. Indeed, the bundling and warm issues are now the real prevention to accomplishing higher power densities. For the most part, bundling and warm concerns should be tended to at every last level, Clearly, there are distinct packaging and hot views around the streamlining revolve at distinct rates. For illustration, while at the level of the device the consideration is to minimize the parasitic and warm impedance of the pack, the power thickness and the profitability of the cooling may be at the level of the structure.

\section{CONCLUSION}

A supported forceful development of the Internet framework and a generally low vitality effectiveness of energy conveyance frameworks of web gear alongside an increasing expense of vitality and ecological concerns has brought productivity streamlining over the whole load extend into the front line of the present datacom hardware execution prerequisites. Future imperative developments in the growth of power supply must meet this to an exceptional degree testing effort, which is also escalated by the ever-present need for greater energy densities. While the actual execution modifications were primarily grown by refinements of topology and advances in semiconductor performance and attractive elements, potential effectiveness and energy thickness overhauls are depended upon to in a general sense begin from system building streamlining and control administration, and in addition from headways in bundling and warm administration strategies.

\section{REFERENCES}

1. Dutta P., Kumaravel A.,A novel approach to trust based identification of leaders in social networks, Indian Journal of Science and Technology,V-9,I-10,PP--,Y-2016

2. Kumaravel A., Dutta P.,Application of Pca for context selection for collaborative filtering,Middle - East Journal of Scientific Research,V-20,I-1,PP-88-93,Y-2014

3. Kumaravel A., Rangarajan K.,Constructing an automaton for exploring dynamic labyrinths,2012 International Conference on Radar, Communication and Computing, ICRCC 2012,V-,I-,PP-161-165,Y-2012

4. P. Kavitha, S. Prabakaran "Adaptive Bilateral Filter for Multi-Resolution in Brain Tumor Recognition" International Journal of Innovative Technology and Exploring Engineering (IJTEE) ISSN: 2278-3075, Volume-8 Issue-8 June, 2019

5. Kumaravel A.,Comparison of two multi-classification approaches for detecting network attacks, World Applied Sciences Journal,V-27,I-11,PP-1461-1465,Y-2013

6. Tariq J., Kumaravel A.,Construction of cellular automata over hexagonal and triangular tessellations for path planning of multi-robots,2016 IEEE International Conference on Computational Intelligence and Computing Research, ICCIC 2016,V-,I-,PP--,Y-2017
7. Sudha M., Kumaravel A.,Analysis and measurement of wave guides using poisson method,Indonesian Journal of Electrical Engineering and Computer Science,V-8,I-2,PP-546-548,Y-2017

8. Ayyappan G., Nalini C., Kumaravel A.,Various approaches of knowledge transfer in academic social network,International Journal of Engineering and Technology,V-,I-,PP-2791-2794,Y-2017

9. Kaliyamurthie, K.P., Sivaraman, K., Ramesh, S. Imposing patient data privacy in wireless medical sensor networks through homomorphic cryptosystems 2016, Journal of Chemical and Pharmaceutical Sciences 92.

10. Kaliyamurthie, K.P., Balasubramanian, P.C. An approach to multi secure to historical malformed documents using integer ripple transfiguration 2016 Journal of Chemical and Pharmaceutical Sciences 92.

11. A.Sangeetha,C.Nalini,"Semantic Ranking based on keywords extractions in the web", International Journal of Engineering \& Technology, 7 (2.6) (2018) 290-292

12. S.V.GayathiriDevi,C.Nalini,N.Kumar,"An efficient software verification using multi-layered software verification tool "International Journal of Engineering \& Technology, 7(2.21)2018 454-457

13. C.Nalini,ShwtambariKharabe,"A Comparative Study On Differen Techniques Used For Finger - Vein Authentication”, International Journal Of Pure And Applied Mathematics, Volume 116 No. 8 2017, 327-333, Issn: 1314-3395

14. M.S. Vivekanandan and Dr. C. Rajabhushanam, "Enabling Privacy Protection and Content Assurance in Geo-Social Networks", International Journal of Innovative Research in Management, Engineering and Technology, Vol 3, Issue 4, pp. 49-55, April 2018.

15. Dr. C. Rajabhushanam, V. Karthik, and G. Vivek, "Elasticity in Cloud Computing", International Journal of Innovative Research in Management, Engineering and Technology, Vol 3, Issue 4, pp. 104-111, April 2018.

16. K. Rangaswamy and Dr. C. Rajabhushanamc, "CCN-Based Congestion Control Mechanism In Dynamic Networks", International Journal of Innovative Research in Management, Engineering and Technology, Vol 3, Issue 4, pp. 117-119, April 2018.

17. Kavitha, G., Kavitha, R., "An analysis to improve throughput of high-power hubs in mobile ad hoc network" , 2016, Journal of Chemical and Pharmaceutical Sciences, Vol-9, Issue-2: 361-363

18. Kavitha, G., Kavitha, R., "Dipping interference to supplement throughput in MANET" , 2016, Journal of Chemical and Pharmaceutical Sciences, Vol-9, Issue-2: 357-360



\section{AUTHORS PROFILE}

C. Rajabhushnam, Associate Professor, Department of Computer Science \& Engineering, Bharath Institute of Higher Education and Research, Chennai, India



B. Sundar Raj Assistant Professor, Department of Computer Science \& Engineering, Bharath Institute of Higher Education and Research,

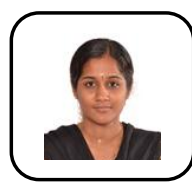
Chennai, India

Sri Vidhya, Assistant Professor, Department of Computer Science \& Engineering, Bharath Institute of Higher Education and Research,

Chennai, India 